\title{
Effects of cultivation methods and cultivars on the incidence of major insect pest of rice
}

\author{
VIJAY KUMAR SONI* AND S.N. TIWARI ${ }^{1}$
}

S.K. College of Agriculture and Research Station (IGKV), KAWARDHA(KABIRDHAM) (C.G.) INDIA

${ }^{1}$ Department of Entomology, G.B. Pant University of Agriculture and Technology, Pantnagar, U.S. NAGAR, (UTTARAKHAND) INDIA

\section{ARITCLE INFO}

Received : 19.01 .2016

Revised : 03.02 .2016

Accepted : 17.02 .2016

KEY WORDS :

Cultivation methods, Direct seeded, Insect pest, Rice, Transplanting
*Corresponding author: Email: vijay.soniji@gmail.com

\begin{abstract}
The field experiment were conducted on effects of cultivation methods and cultivars on the incidence of major insect pest of rice at Norman E. Borloug Crop Research Centre, G.B. Pant University of Agriculture and Technology, Pantnagar, Uttarakhand, India during Kharif 2012. Normal transplanted and direct seeded cultivation systems of rice hybrids (KRH-2) and high yielding variety (HKR-47) were sown. Sprouted seeds of KRH-2 and HKR-47 was dibbled in lines for direct seeding and the same sprouted seed was sown on the same day in nursery for transplanting in field. Date of sowing was same under both the systems. Results revealed that infestation of rice stem borer was significantly higher in transplanted rice as compared to direct seeded rice. In direct seeded rice the infestation was significantly higher in hybrid KRH-2 as compared to high yielding variety HKR-47.The population of brown plant hopper (BPH) was higher in direct seeded rice as compared to transplanted rice, however, such differences appeared due to delayed incidence of BPH in higher number after 70 days after transplanting (DAT). The mean population of white backed plant hopper (WBPH) was higher in transplanted rice as compared to direct seeded rice and more hoppers were seen in KRH-2 as compared to HKR-47. Significantly higher gundhi bug damage (5.8\%) to the grains was found in transplanting (KRH-2).
\end{abstract}

How to view point the article : Soni, Vijay Kumar and Tiwari, S.N. (2016). Effects of cultivation methods and cultivars on the incidence of major insect pest of rice. Internat. J. Plant Protec., 9(1) :21-25. 